\title{
MODEL FOR RELIABILITY PREDICTION OF THICK FILM RESISTORS ${ }^{\dagger}$
}

\author{
R.B. PRANCHOV \\ On leave of absence at Loughborough University of Technology from the \\ Higher Institute of Mechanical and Electrical Engineering, Telecommunication Department, \\ 1156 Sofia, Bulgaria \\ D.S. CAMPBELL \\ Department of Electronic and Electrical Engineering, Loughborough University of Technology, \\ Loughborough, Leicestershire, U.K.
}

\begin{abstract}
A model for time-to-failure prediction based on component parameter drift is described. The idea for creation of this model is based on the influence of time-dependent random and non random factors on the distribution of the random variable.

The reliability interpretation of the data from thick film resistor ageing tests has been completed with the model developed. Two different drift functions are described for two ruthenium-based thick film methods with equal resistivity $-10 \Omega /$ square. The values of the functional parameters depend strongly on the storage test temperature. Mean time-to-failure decreases approximately 4 times with an increase of storage temperature of $20 \mathrm{deg}$. C.
\end{abstract}

\section{INTRODUCTION}

The estimation of electronic component reliability from accelerated life test data is possible only if an appropriate linear model for the connection between the accelerated life test data and the normal working conditions exists. For instance, the Arrhenius model is one of the most well-known linear models. The application of a linear model is based on the assumption that the ageing processes are the same under accelerated and normal tests. In accordance with the principle of "heredity" in reliability theory", this means that the distribution of time-to-failure must be the same, independently of the test conditions. For some electronic components with stable parameters in a narrow temperature interval, it will not be possible to obtain enough data from a practical point of view, while accelerating the ageing processes and also observing the principle of "heredity". In such cases decreasing the necessary time for reliability estimation may be done through prediction based on a parameter drift function. A similar method for the estimation of failure rate function has been developed ${ }^{6}$ where the author gave an illustrative example for the estimation of the failure rate function of transistors.

The subject under investigation in this paper is the possibility of decreasing the time for reliability estimation of thick film resistors (TFRs). The results published from investigations of the conductivity in TFRs show that there are several conduction mechanisms connected with the two main materials in the thick film-metal and glass. ${ }^{1,5,8}$ Different mechanisms have a predominant influence in different narrow temperature intervals. This means that the processes which cause the resistance drift of TFRs will be different at different temperatures and the application of the Arrhenius model will be inaccurate or even impossible. This conclusion is true even for low resistance TFRs, in which the metal phase is predominant. ${ }^{8}$

If the use of the Arrhenius model cannot give accurate results, the alternative possibility for decreasing the time for reliability estimation is the use of reliability prediction based on resistance drift and this is examined in this paper.

\footnotetext{
†Paper originally presented at the 4th European Hybrid Microelectronics Conference, Copenhagen, May 1983. Paper received in final form 1.6.83.
} 


\section{MODEL FOR RELIABILITY PREDICTION}

The idea of this model is based on the influence of time-dependent random and nonrandom factors on the distribution of the random variables. ${ }^{9}$ For an initial normal distribution (commonly accepted for electronic component production) the influence of the parameter drift on the probability density function, (p.d.f.), $f_{t}(x)$, can be presented as:-

$$
f_{t}(x)=\frac{1}{S(t) \sqrt{ } 2 \pi} \exp \left\{-\frac{[x(t)-\bar{x}(t)]^{2}}{2 S^{2}(t)}\right\}
$$

where $S(t)$ is the standard deviation at time, $t, x(t)$ is the parameter value, and $\bar{x}(t)$ is the mean value at time, $t$.

Let the drift be linear, e.g.:-

$$
x_{i}(t)=x_{i}(0)+c_{i} t
$$

where $x_{i}(t)$ is the parameter value of item $i$ in a group of $n$, at time, $t, x_{i}(0)$ is the initial parameter value of item $i$, and $c_{i}$ is a constant for item $i$. Equation (2) may be written:-

$$
\Delta \mathrm{x}_{\mathbf{i}}(\mathrm{t})=\mathrm{c}_{\mathbf{i}} \mathrm{t}
$$

If $x_{i}(0)$ and $c_{i}$ are statistically independent random variables, then

$$
\overline{\Delta x}(\mathrm{t})=\overline{\mathrm{c} t}
$$

and

$$
S^{2}(\Delta x)=S^{2}(c) t^{2}
$$

where $\overline{\Delta x}(t)$ is the mean value of the parameter changes of all items and $\bar{c}$ is the mean value of the constant $c_{i}$.

If $x(0)$ and $c$ have a normal distribution, it will be possible to substitute (4) in (1), thus:-

$$
f_{t}(\Delta x)=\frac{1}{S(c) t \sqrt{ } 2 \pi} \exp \left\{-\frac{\left(\Delta x-{ }^{-\bar{t}}\right)^{2}}{2 t^{2} S^{2}(c)}\right\}
$$

For every moment, $t_{j}$, the distribution of p.d.f. in equation (5) will be normal, with mean value, $\bar{c} t_{j}$, and standard deviation, $S(c) t_{j}$. The probability, $P(\Delta x)$, that the random variable is at the limits $(\alpha, \beta)$ may be simply calculated as:-

$$
\mathrm{P}(\Delta \mathrm{x})=\phi\left\{\frac{\beta-\overline{\mathrm{ct}}}{\mathrm{S}(\mathrm{c}) \mathrm{t}}\right\}-\phi\left\{\frac{\alpha-\overline{\mathrm{ct}}}{\overline{\mathrm{S}(\mathrm{c}) \mathrm{t}}}\right\}
$$

where $\phi($.$) is the standard normal cumulative distribution function.$

From equation (6) it is easy to calculate the time $t_{p}$ at which the parameter drift will reach the limits $(\alpha, \beta)$ for $(1-\mathrm{P}) .100 \%$ of the components tested, or alternatively - the percentage of the failures in a given period of time. 


\section{EXPERIMENTAL RESULTS AND DISCUSSION}

The batches of 45 untrimmed TFRs, each produced with two different resistive pastes, Electroscience ESL 2911 and ESL 3111, were tested. ESL 9633B(Ag/Pd) was used as the conductive paste. The substrates used were $96 \%$ Alumina and the resistors were fired according to the manufacturers instructions. ${ }^{3}$ The layout diagram used is shown in Figure 1. (Each resistor was $0.5 \times 0.5 \mathrm{~cm}$ ).

The storage test temperatures used were $50^{\circ} \mathrm{C}, 70^{\circ} \mathrm{C}$ and $105^{\circ} \mathrm{C}$.

The dependence of the mean value of the resistance drift, $\Delta R / R$, on testing time for some of the TFRs (ESL 2911) is shown in Figure 2.

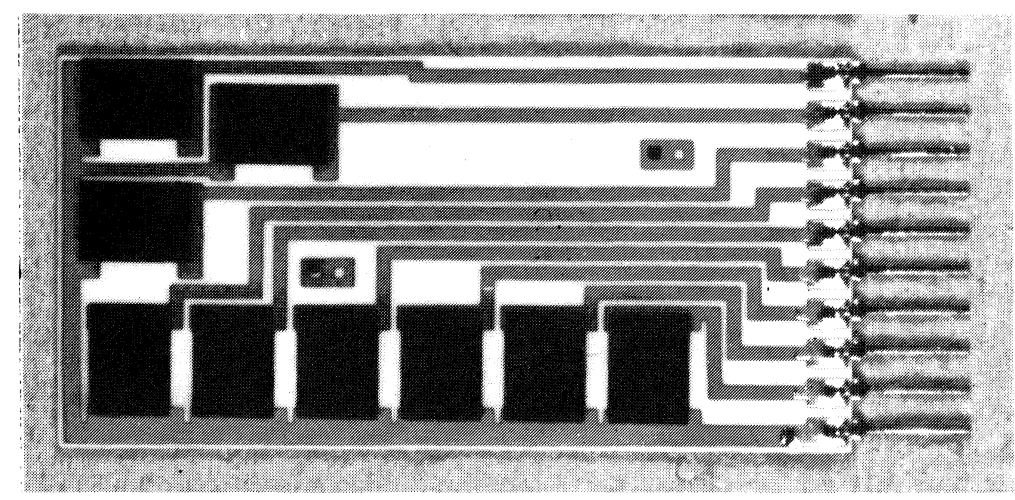

FIGURE 1 Resistor test pattern (substrate size $2^{\prime \prime} \times 1^{\prime \prime}$ )

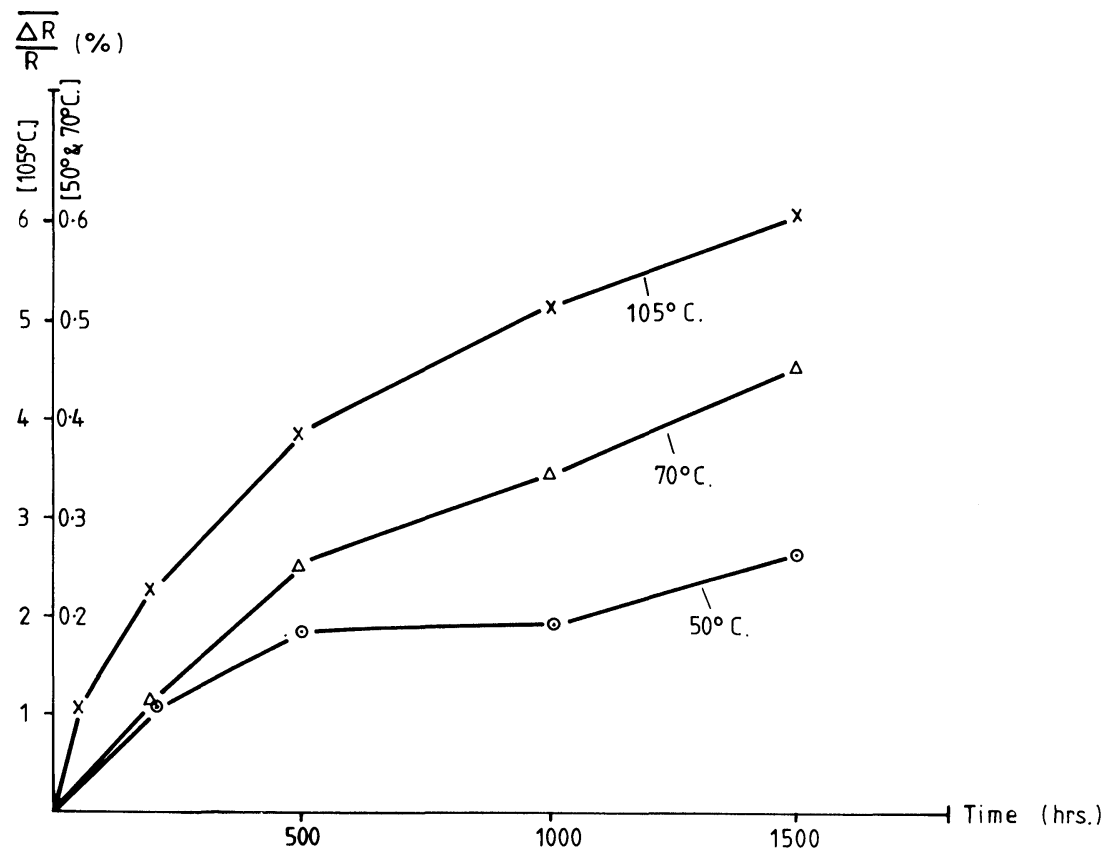

FIGURE 2 Mean value of resistance drift for TFRs (ESL 2911) at three storage temperatures 
The approximation function is:-

$$
\Delta \mathrm{R} / \mathrm{R}=\mathrm{ct}^{1 / 2}
$$

where $\mathrm{c}$ is as defined in equation (2).

A similar dependence has been recognised by Sinnadurai et $\mathrm{a}^{10}$ and for some TFRs a change of the value of $c$ is observed when the resistance change exceeded about $1 \%$ which "is consistent with a change in the diffusion coefficient to a new value". Similar changes of the value of $\mathrm{c}$ have not been observed in the tests under consideration regardless of the much bigger changes of the resistance (curve III - Figure 2). For the purposes of reliability prediction it is very important that the coefficients of the approximation function of the parameter drift be unchangeable during the whole working life. It would be incorrect to undertake reliability prediction if it had not been established that the drift function was unchangeable during the time considered. Furthermore, if the drift function was a variant, any reliability prediction would be inaccurate.

Because of the large drift (over $5 \perp_{\perp} \%$ ) and the unchangeable coefficient, c, it is possible to assume that the mean value of $c$ is the same at all the times considered.

The dependence of the mean value of the resistance drift on time for the TFRs (ESL 3111) is shown in Figure 3.

The approximation function used here is:-

$$
\Delta \mathrm{R} / \mathrm{R}=\mathrm{c}^{\prime} \mathrm{t}
$$

where $c^{\prime}$ is another constant.

It is interesting to notice that the two pastes examined are both ruthenium based, with the same sheet resistance $(10 \Omega / \mathrm{sq})$ and produced by the same manufacturer. However, the drift function is different for the two materials which shows how sensitive is the conduction mechanism to changes in the paste ingredients and the firing

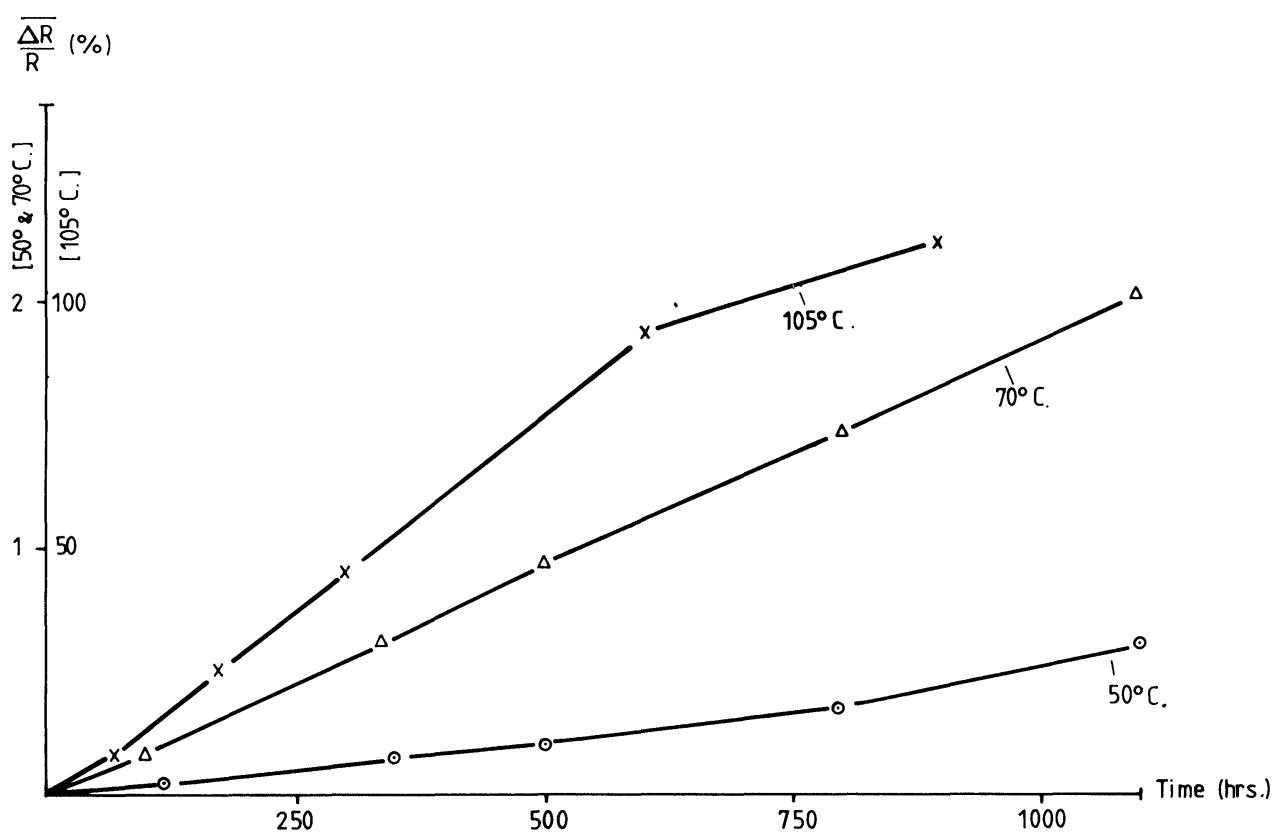

FIGURE 3 Mean value of resistance drift for TFRs (ESL 3111) at three storage temperatures 
conditions. The drift to such high value as over $100 \%$ for a $900 \mathrm{hrs}$ test at $105^{\circ} \mathrm{C}$ (curve III, Figure 3) is still in accordance with the linear function and because of that it is possible to assume that the coefficient of the linear function is the same for the whole working life. Similar linear theoretical and practical drift functions have been discussed by Bjocklund and Linde. ${ }^{2}$

The test results obtained are given in Table I. The $\chi^{2}$ test of goodness-of-fit is used for the normal distribution, ${ }^{4}$ and, in Table I, are included the values of the level of confidence.

TABLE I

Resistance data and statistical results obtained using ESL 2911 and 3111

\begin{tabular}{lllllllll}
\hline $\begin{array}{l}\text { Type of } \\
\text { paste }\end{array}$ & $\begin{array}{l}\text { Test } \\
\text { temperature }\end{array}$ & $\mathrm{R}_{0}(\Omega)$ & $\mathrm{S}\left(\mathrm{R}_{0}\right)(\Omega)$ & $\begin{array}{l}\text { Level of } \\
\text { confid. } \\
\left(\chi^{2} \text { test }\right)\end{array}$ & $\begin{array}{l}\overline{\mathrm{c}} \\
\left(\times 10^{3}\right)\end{array}$ & $\begin{array}{l}\mathrm{S}(\mathrm{c}) \\
\left(\times 10^{3}\right)\end{array}$ & $\begin{array}{l}\text { Level of } \\
\text { confid. } \\
\left(\chi^{2} \text { test }\right)\end{array}$ & $\begin{array}{l}\text { Correlation } \\
\text { Coef. }\end{array}$ \\
\hline ESL 2911 & $50^{\circ} \mathrm{C}$ & 23.94 & 1.52 & $40 \%$ & 5.45 & 2.53 & $40 \%$ & 0.012 \\
$\left(\Delta \mathrm{R} / \mathrm{R}=\mathrm{ct}^{1 / 2}\right)$ & $70^{\circ} \mathrm{C}$ & 23.16 & 1.03 & $30 \%$ & 10.7 & 3.147 & $90 \%$ & -0.10 \\
& $105^{\circ} \mathrm{C}$ & 23.64 & 1.47 & $30 \%$ & 164 & 10.8 & $60 \%$ & -0.011 \\
\hline $\mathrm{ESL} \mathrm{3111}$ & $50^{\circ} \mathrm{C}$ & 22.65 & 1.29 & $20 \%$ & 0.437 & 0.166 & $25 \%$ & -0.14 \\
$\left(\Delta \mathrm{R} / \mathrm{R}=\mathrm{c}^{\prime} \mathrm{t}\right)$ & $70^{\circ} \mathrm{C}$ & 22.92 & 1.13 & $20 \%$ & 1.895 & 0.29 & $40 \%$ & -0.20 \\
\hline
\end{tabular}

From the drift function, equation (7), equation (6) for TFRs (ESL 2911) can be written:-

$$
P\left(\frac{\Delta R}{R}\right)=\phi\left\{\frac{\beta-\overline{c t^{-1 / 2}}}{S(c) t^{1 / 2}}\right\}-\phi\left\{\frac{\alpha-\bar{c} t^{1 / 2}}{S(c) t^{1 / 2}}\right\}
$$

The calculations of the time-to-failure of TFRs (ESL 2911) can be performed using equation (9) and that of the TFRs (ESL 3111) with equation (6), since the drift function, equation (8), is linear.

In view of the data available for stability as a function of application for the pastes used, ${ }^{3}$ the possible resistance change is $\pm 1 \%$ for ESL 2911 and $10 \%$ for ESL 3111. Change beyond these limits will be considered as failures. The time-to-failure calculated from equation (9) for TFRs (ESL 2911) and from equation (6) for TFRs (ESL 3111) are given in Table II.

TABLE II

Predicted time-to-failure

\begin{tabular}{|c|c|c|c|c|c|c|c|c|}
\hline \multirow{2}{*}{$\begin{array}{l}\text { Type of } \\
\text { TF } \\
\text { paste }\end{array}$} & \multirow{2}{*}{$\begin{array}{l}\text { Failure } \\
\text { limits } \\
(\Delta R / R)\end{array}$} & \multirow{2}{*}{$\begin{array}{l}\text { Test } \\
\text { temperature }\end{array}$} & \multicolumn{6}{|c|}{ Time-to-failure, (hrs) } \\
\hline & & & $\begin{array}{l}(1-\mathrm{P}) \\
100=2 \%\end{array}$ & $\begin{array}{l}(1-\mathrm{P}) \\
100=10 \%\end{array}$ & $\begin{array}{l}(1-\mathrm{P}) \\
100=20 \%\end{array}$ & $\begin{array}{l}(1-P) \\
100=50 \%\end{array}$ & $\begin{array}{l}(1-P) \\
100=80 \%\end{array}$ & $\begin{array}{l}(1-\mathrm{P}) \\
100=90 \%\end{array}$ \\
\hline $\begin{array}{l}\text { ESL } \\
2911\end{array}$ & $\pm 1 \%$ & $\begin{array}{r}50^{\circ} \mathrm{C} \\
70^{\circ} \mathrm{C} \\
105^{\circ} \mathrm{C}\end{array}$ & $\begin{array}{r}8855 \\
3370 \\
29\end{array}$ & $\begin{array}{r}13265 \\
4563 \\
32\end{array}$ & $\begin{array}{r}17444 \\
5444 \\
34\end{array}$ & $\begin{array}{r}33667 \\
8613 \\
37\end{array}$ & $\begin{array}{r}90251 \\
15124 \\
42\end{array}$ & $\begin{array}{r}203359 \\
21968 \\
45\end{array}$ \\
\hline $\begin{array}{l}\text { ESL } \\
3111\end{array}$ & $\pm 10 \%$ & $\begin{array}{r}50^{\circ} \mathrm{C} \\
70^{\circ} \mathrm{C} \\
105^{\circ} \mathrm{C}\end{array}$ & $\begin{array}{r}12865 \\
4017 \\
54\end{array}$ & $\begin{array}{r}15397 \\
4413 \\
59\end{array}$ & $\begin{array}{r}17348 \\
4676 \\
63\end{array}$ & $\begin{array}{r}22853 \\
5277 \\
70\end{array}$ & $\begin{array}{r}33607 \\
6055 \\
80\end{array}$ & $\begin{array}{r}44539 \\
6563 \\
86\end{array}$ \\
\hline
\end{tabular}

$2 \%$ from a batch of 45 TFRs is approximately 1 resistor and it can be seen from Table II that 1 resistor will fail after $8855 \mathrm{hrs}$. at $50^{\circ} \mathrm{C}$ for the TFRs (ESL 2911) and after $12865 \mathrm{hrs}$. at $50^{\circ} \mathrm{C}$ for the TFRs (ESL 3111). It is possible to compare the predicted mean time-to-failure $((1-\mathrm{P}) \cdot 100=50 \%)$ from Table II with achieved mean time-to- 
failure at the $105^{\circ} \mathrm{C}$ storage tests (Figures 2 and 3). For example, the mean time-tofailure for TFRs (ESL 3111) from Table II is $70 \mathrm{hrs}$. and from Figure 3 is $80 \mathrm{hrs}$. A more sensitive comparison between predicted and real mean time-to-failure would require more detailed measurement of drift, particularly in the early stages.

\section{CONCLUSIONS}

A model for time-to-failure prediction based on the component parameter drift is developed. The model is created on the assumption that initial values of the component parameter and the functional parameters of the drift function are statistically independent and normally distributed random variables. The reliability interpretation of the data from TFR ageing tests has been completed with the present model. The drift function for

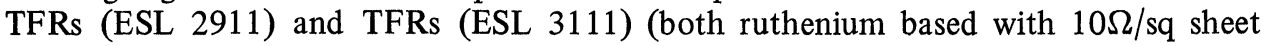
resistance) are different. This shows that it is not possible to judge the resistance drift function for one particular thick resistive film from the data about another thick film, even if the two films are produced with the pastes from the same series but with different resistivity.

The big differences obtained for the function parameters at the three test temperatures $50^{\circ} \mathrm{C}, 70^{\circ} \mathrm{C}$ and $105^{\circ} \mathrm{C}$ (Table I) confirm that the conduction mechanism is stable in a very narrow temperature interval, even for low resistance TFRs. ${ }^{8}$ Small increases of the storage temperature leads to large changes in the functional parameters of the drift function and increases in the failure rate (time-to-failure decreases approximately 4 times with an increase in temperature of $20^{\circ} \mathrm{C}$ ).

\section{REFERENCES}

1. M.P. Ansell, 'Conduction processes in thick film resistors' (Part I and II), Electrocom. Sci. and Tech. 3, pp 131-151, (1976).

2. G. Bjocklund and L. Linde, 'Optimization of thick film resistors for low drift' Electrocomp. Sci. and Tech. 7, pp 87-91, (1980).

3. Electronic Materials Systems, Electro Science Laboratories, Inc. Handbook. 1980.

4. R.S. Burington and D.C. May, Handbook of Probability and Statistics with Tables McGraw-Hill, New York, 1970.

5. R.M. Hill, 'Electrical transport in thick film resistors' Electrocomp. Sci. and Tech. 6, pp. 141$145,(1980)$.

6. J. M $\phi$ ltoft, 'The failure rate function estimated from parameter drift measurements'. Microel. and Reliab., 20, pp 787-802, (1980).

7. A.I. Perrote, G.D. Kartashov and C.N. Tzvetaev, 'Fundamentals of accelerated life tests'. Pub. by Sov. Radio. Moscow. 1980 (in Russian).

8. M. Prudenziati, 'Conduction mechanism in thick-film resistors' Proc. Third European Hybrid Microelectr. Conf., pp 1-10, (1981).

9. G. Savov and R. Pranchov, 'Production technology of electronic equipment' Pub. by Technica. Sofia, (1981). (In Bulgarian).

10. F.N. Sinnadurai, P.E. Spencer and K.J. Wilson, 'Some observations on the accelerated ageing of thick film resistors'. Electrocomp. Sci. and Tech., 6, pp 241-246, (1980). 

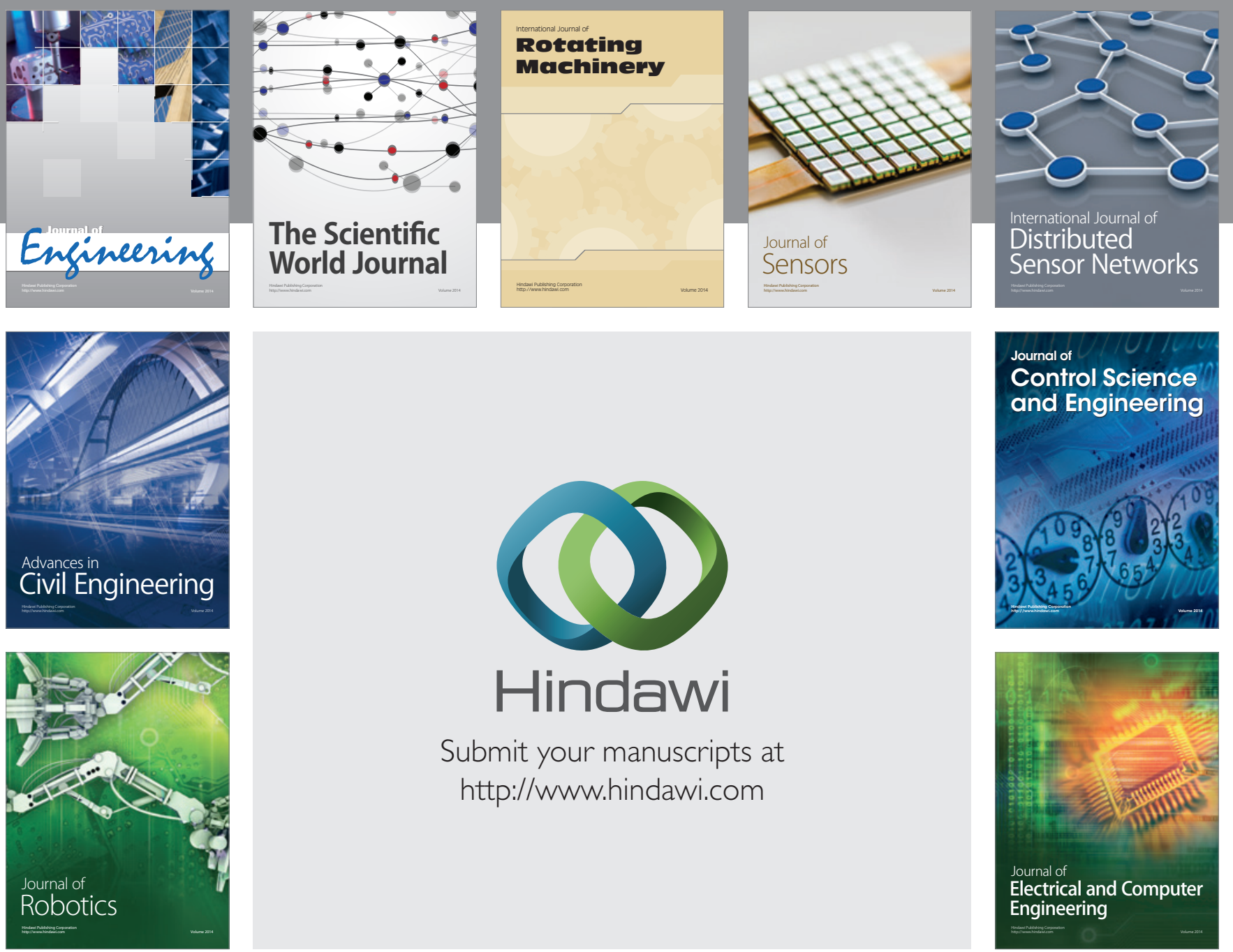

Submit your manuscripts at

http://www.hindawi.com
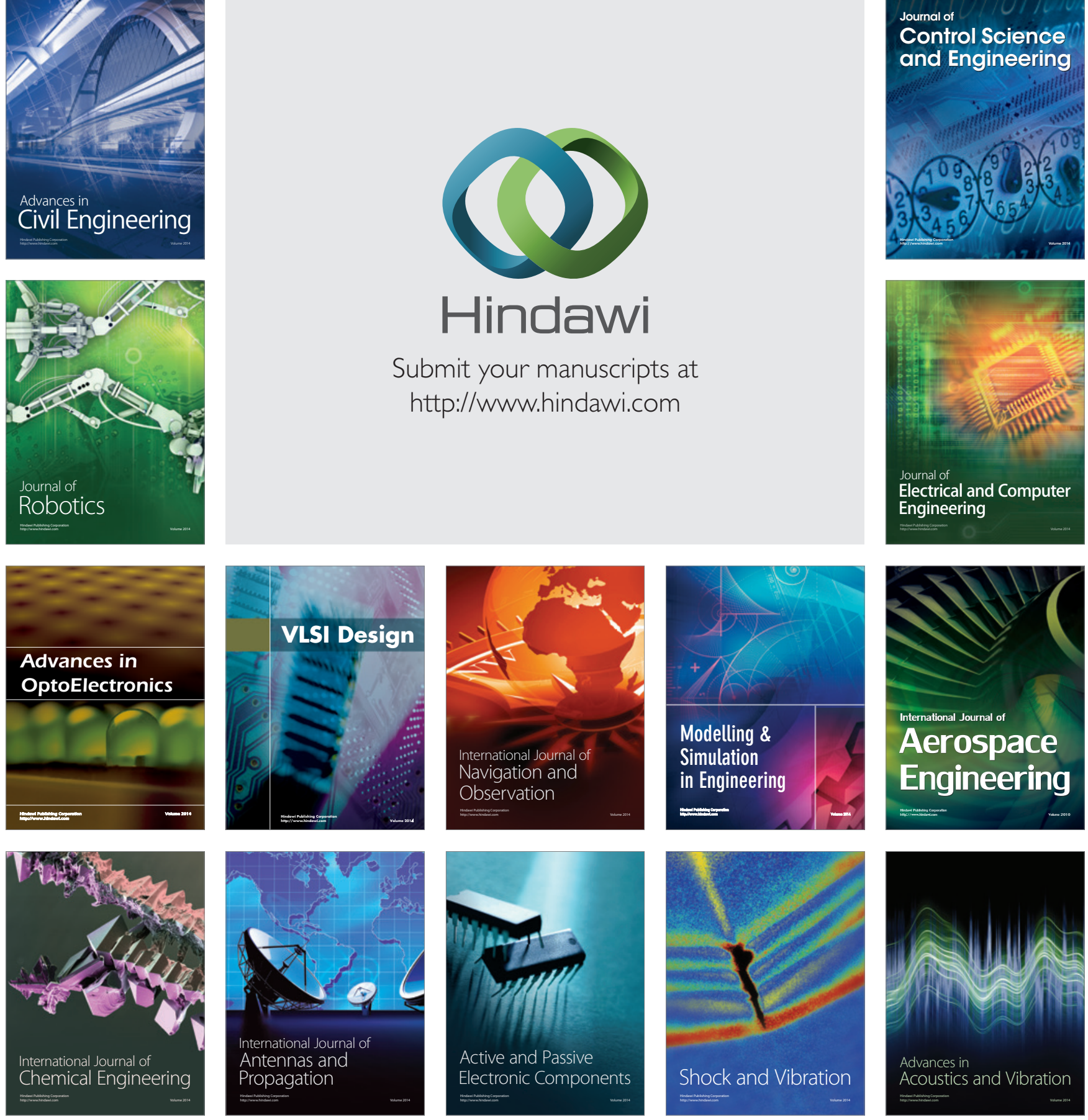